\title{
A Permanent-Magnet Hybrid Brushless Integrated Starter-Generator for Hybrid Electric Vehicles
}

\author{
Chunhua Liu, Member, IEEE, K. T. Chau, Senior Member, IEEE, and J. Z. Jiang
}

\begin{abstract}
A new permanent-magnet (PM) hybrid brushless (PMHB) machine is proposed and implemented as the integrated starter-generator (ISG) for hybrid electric vehicles (HEVs). It has the advantages of higher torque density than other PMHB machines and much wider speed range than other PM brushless machines. The key is to tune its dc-field winding current in such a way that three major modes of ISG system operation for HEVs, namely, engine cranking, battery charging, and torque boosting, can be achieved effectively. The finite-element method is employed to simulate its steady-state and dynamic performances. Finally, a $2-\mathrm{kW}$ prototype is constructed and tested to experimentally verify the simulation results and the validity of the proposed ISG system.
\end{abstract}

Index Terms-Hybrid electric vehicle (HEV), hybrid field excitation, integrated starter-generator (ISG), permanent-magnet (PM) machine.

\section{INTRODUCTION}

D UE TO growing concerns on environment protection and energy conservation, the development of energy-efficient technologies for hybrid electric vehicles (HEVs) has taken on an accelerated pace [1]-[3]. Electric machines and drives are one of the key energy-efficient technologies for HEVs [4]-[6]. In a conventional automotive electrical system, because most of the electric machines cannot offer high starting torque and wide speed range simultaneously, the starter motor and the generator have to be separately employed for engine cranking and battery charging, respectively [7], [8]. With the advancement of electric machines and power electronics technologies, the integrated starter-generator (ISG), which performs both engine cranking and battery charging, is becoming attractive for modern automobiles and HEVs [9]-[11].

In recent years, various types of electric machines have been utilized as ISG for automobiles and HEVs. The induction machine is one of the main candidates, since it has a wide speed range and high reliability [12]. However, it suffers from complicated flux control, particularly for field weakening. The switched-reluctance (SR) machine is also proposed for ISG application due to its simple and robust structure [13], [14]. However, it suffers from the disadvantages of low power

Manuscript received June 14, 2009; revised December 1, 2009; accepted February 2, 2010. Date of publication March 1, 2010; date of current version November 10, 2010. This work was supported by the Research Grants Council, Hong Kong Special Administrative Region, China, under Grant HKU 710710E.

C. Liu and K. T. Chau are with the Department of Electrical and Electronic Engineering, The University of Hong Kong, Hong Kong (e-mail: chualiu@eee. hku.hk; ktchau@eee.hku.hk).

J. Z. Jiang is with the Department of Automation, Shanghai University, Shanghai 200072, China (e-mail: jzhjiang@ mail.shu.edu.cn).

Color versions of one or more of the figures in this paper are available online at http://ieeexplore.ieee.org.

Digital Object Identifier 10.1109/TIE.2010.2044128 density, low efficiency, and high torque ripple, making it less attractive. The permanent-magnet (PM) brushless machine is another attractive candidate, since it inherently offers high power density and high efficiency [15], [16]. However, because of the difficulty in flux control, its constant-power speed range is limited. Consequently, different control strategies are developed to extend its speed range [16], [17], but they are associated with the drawback of complex control.

In recent years, a new kind of PM brushless machines, called the PM hybrid brushless (PMHB), has been proposed. Initially, the hybrid field excitation was used to simply reduce the field-power requirement [18]. Then, the use of the hybrid field excitation was extended to perform field weakening in the radial-flux PM claw-type brushless machine [4], the axialflux double-rotor single-stator PM disk machine [19], and the transverse-flux consequent-pole PM machine [20]. However, they all suffer from the drawback of complicated structures and the use of rotor-PM brushless machine topologies. Very recently, the hybrid field excitation has been further extended to stator-PM brushless-machine topologies for wind-power generation [21]. Nevertheless, the development of hybrid field excitation for ISG is absent in literature.

In this paper, a new PMHB machine is proposed and implemented as the ISG for HEVs, which is superior to the existing PMHB machines for various ISG operations such as engine cranking and battery charging. Different from the conventional machine used for the ISG, the proposed machine will adopt hybrid excitations (PMs and dc-field windings) to produce magnetic field. Hence, with the capability of flexible airgap flux control, the proposed machine will not only provide a high starting torque for cranking but also offer constant generated voltage for battery charging over wide ranges of speeds and loads.

Section II will describe the system configuration and its operation modes. In Section III, the proposed PMHB-machinebased ISG system will be presented. Section IV will be devoted to introducing the circuit-field-torque time-stepping finite-element method (CFT-TS-FEM) for analysis of the proposed machine. The simulation performance at various operation modes will be discussed in Section V. Then, hardware implementation and experimental verification will be given in Section VI. Furthermore, the proposed machine will be compared with its counterpart in Section VII. Finally, a conclusion will be drawn in Section VIII.

\section{System Configuration And Operation Modes}

As shown in Fig. 1, the ISG system performs both engine cranking and battery charging for modern automobiles and 


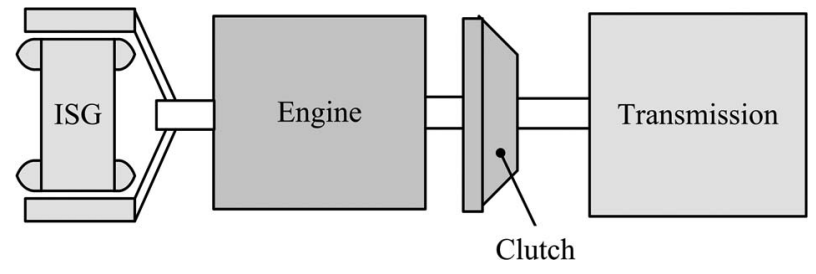

Fig. 1. Modern automotive electrical system using ISG.

HEVs. This ISG system offers three major modes of operation for HEVs.

\section{A. Mode I: Engine Cranking}

When an HEV is started from long-term parking, the ISG works to bring the cold engine up to the required minimum operating speed, the so-called cold cranking. Therefore, the ISG needs to instantaneously provide a high starting torque so as to overcome the substantial resistance of the kinematic mechanism when the engine is cold. For modern HEVs, the engine should be shut down when the vehicle is at rest, the so-called idle stop feature, hence improving fuel economy and reducing exhaust emission for city driving. Therefore, the ISG needs to provide cranking regularly, the so-called warm cranking. Since the engine is warm, the required starting torque is less stringent than that of cold cranking.

\section{B. Mode II: Battery Charging}

Once the engine has taken charge of propulsion, the ISG enters into the battery-charging mode. Since the engine speed generally varies with the vehicle speed, the ISG-generated voltage, and hence the battery voltage, is time-varying. In order to avoid battery overvoltage, and hence to prolong the battery life, the ISG-generated voltage should be kept as less fluctuating as possible. Moreover, when the HEV is braked or runs downhill, the ISG performs regenerative braking to charge the battery, provided that the battery is not yet full or overcharged.

\section{Mode III: Torque Boosting}

When the HEV needs to run uphill or overtaking, the ISG needs to operate in the torque-boosting mode, namely, on top of the full-throttle torque given by the engine, the ISG provides additional instantaneous torque to satisfy the desired command.

\section{PROPOSED ISG SYSTEM}

The proposed ISG system is shown in Fig. 2, which consists of a new PMHB machine, an inverter, and a dc-dc converter. The proposed PMHB machine has a unique feature of hybrid excitation, namely, both PMs and field windings are employed to produce the magnetic field. Different from the traditional PM brushless machine, this machine has a doubly salient structure with 36 salient poles in the stator and 24 salient poles in the rotor. It incorporates armature windings, PMs, and field windings in the stator, while the rotor is simply solid iron core. The outer stator accommodates the armature windings, while

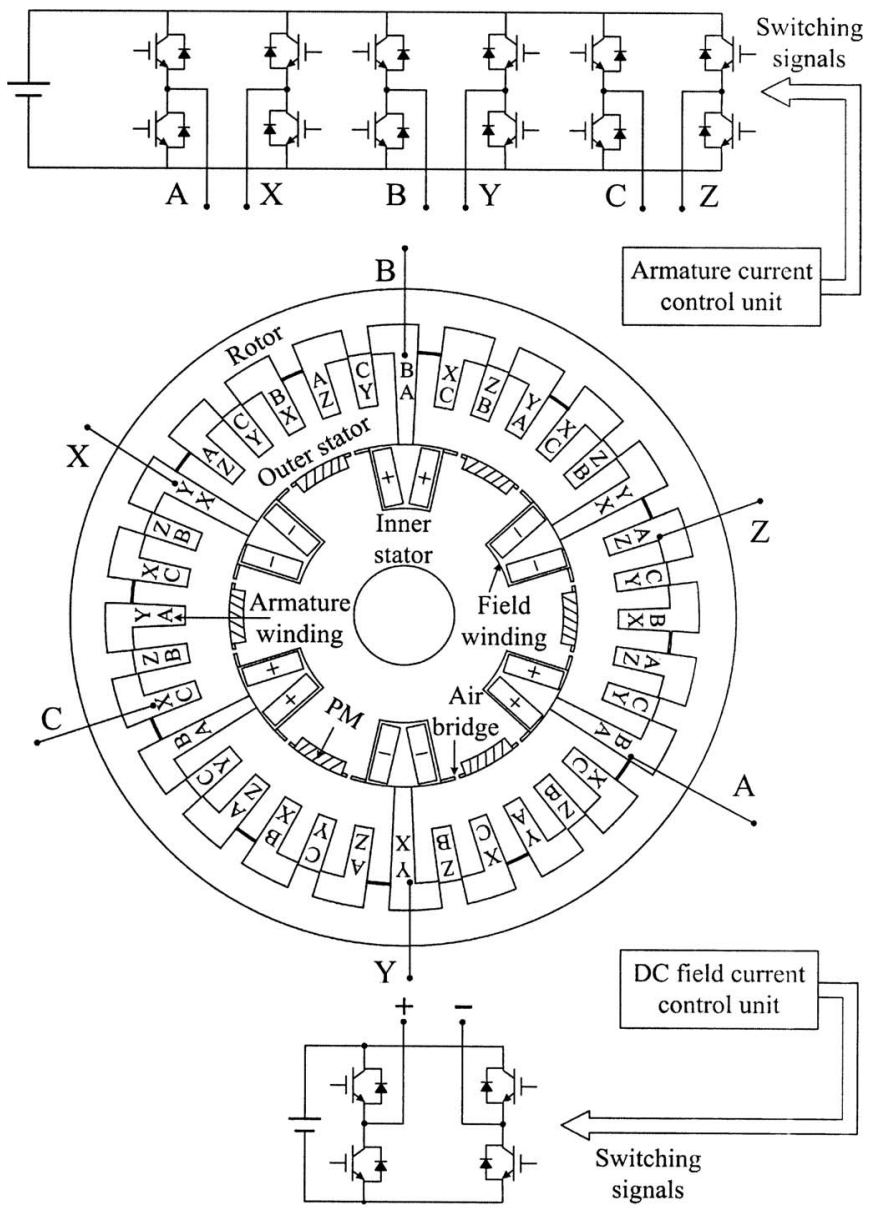

(a)

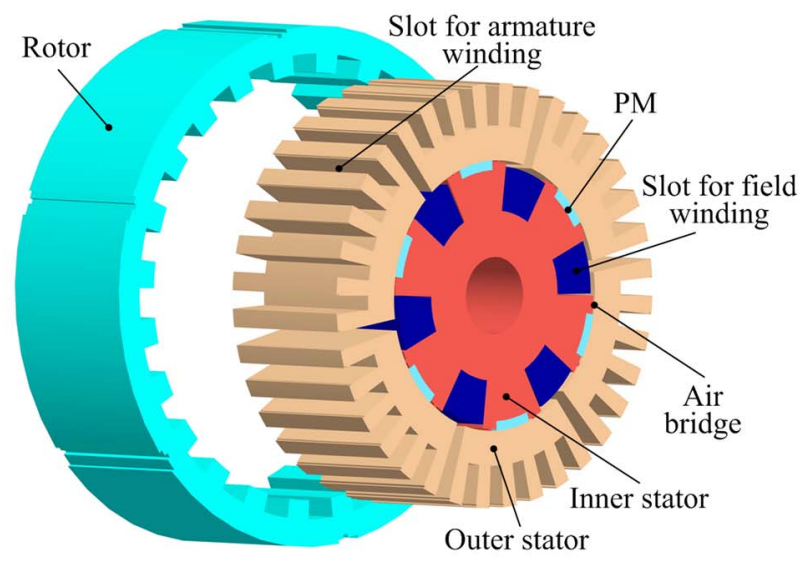

(b)

Fig. 2. Proposed ISG system. (a) System configuration. (b) Machine structure.

the inner stator accommodates both the PMs and field windings. The armature windings adopt a fractional-slot concentrated winding connection, whereas the field windings adopt a simple dc winding connection. Moreover, there is a pair of air bridges in shunt with each PM pole, which functions to suppress the PM flux leakage via the inner stator iron.

With this unique structure, the proposed ISG system offers the following distinct advantages.

1) By tuning the magnitude and direction of the dc-field current, the machine can flexibly regulate the airgap flux. 


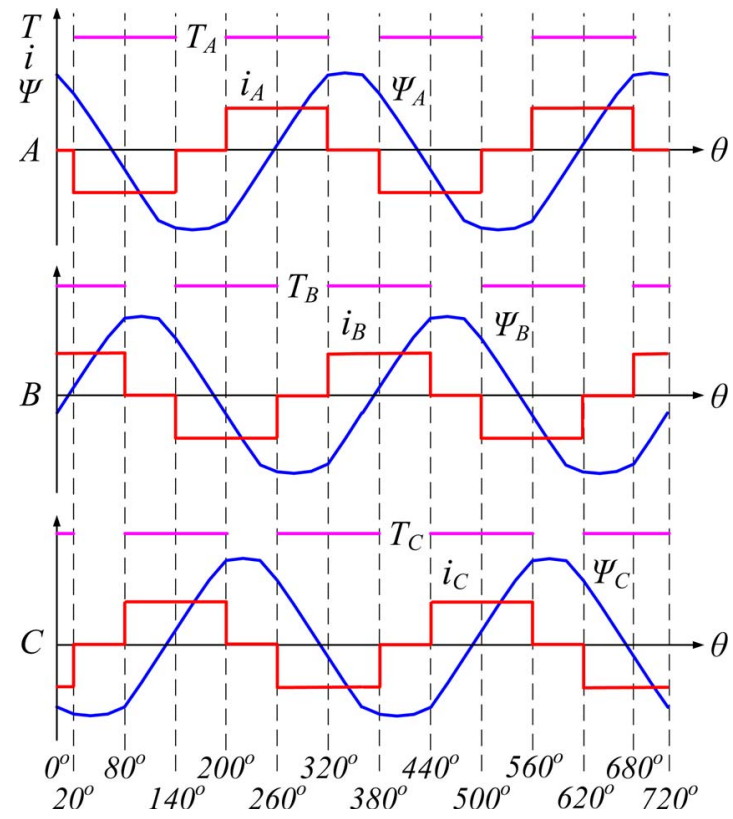

Fig. 3. Principle of machine operation.

Hence, with flux strengthening, the proposed machine can instantaneously provide high starting torque for cold cranking and boosting torque for hill climbing or overtaking. In addition, with online flux control, the machine can maintain constant generated voltage for battery charging over wide ranges of speeds and loads. Additionally, the air bridge functions to amplify the effect of flux weakening when the field MMF is opposing the PM flux.

2) The outer-rotor topology is adopted so that the inner space of the stator can be fully utilized to accommodate the PMs and dc-field windings, hence reducing the overall machine size and improving the torque density. In addition, the rotor has neither PMs nor windings, hence offering high robustness to withstand high-speed or intermittent operation.

3) The fractional-slot armature windings can shorten the magnetic-flux path and the span of end windings, which leads to reduce both iron and copper materials, thus further improving the torque density. In addition, this multipole concentrated winding structure can significantly reduce the cogging torque which usually occurs in conventional PM brushless machines.

4) The full-bridge inverter topology can provide independent phase control of the armature windings, thus offering a fault-tolerant capability for electrical isolation among phases. On the other hand, the full-bridge dc-dc converter topology can provide bidirectional dc current control of the field windings, hence offering flexible flux strengthening and flux weakening.

Fig. 3 shows the principle of operation of the proposed PMHB machine. It is similar to that of the doubly salient PM (DSPM) machine except for the controllable airgap flux. The electromagnetic torque $T_{e}$ of the machine consists of three components, namely, the PM torque component $T_{p m}$ which is due to the interaction between the PM flux linkage $\Psi_{p m}$ and the armature phase current $i$, the dc-field torque component $T_{f}$ which is due to the interaction between the dc-field flux linkage $\Psi_{f}$ and $i$, and the reluctance torque component $T_{r}$ which is due to the variation of the winding inductance $L$. Mathematically, it is given by

$$
T_{e}=T_{p m}+T_{f}+T_{r}=i \frac{d \Psi_{p m}}{d \theta}+i \frac{d \Psi_{f}}{d \theta}+\frac{1}{2} i^{2} \frac{d L}{d \theta}
$$

where $\theta$ is the rotor position. The PM torque component actually dominates the torque production, whereas the reluctance torque component is minor and pulsating with zero average value. Thus, when the flux linkage increases with the rotor position, a positive armature current is applied, hence resulting in a positive torque. When the flux linkage decreases, a negative armature current is applied, also resulting in a positive torque. Meanwhile, the bidirectional dc-field current is used to tune the dc-field flux linkage and hence, the dc-field torque component according to various ISG operation modes.

According to different ISG operation modes, this machine works in the following ways.

1) When the ISG works in Mode I, this machine acts as a motor. A temporary positive dc-field current is applied to instantaneously strengthen the airgap flux, hence achieving a high starting torque for engine cold cranking.

2) When the ISG runs in Mode II, this machine serves as a generator. A positive or negative dc-field current is applied to strengthen or weaken the airgap flux, hence producing a constant generated voltage for battery charging.

3) When the ISG operates in Mode III, this machine also acts as a motor. A short-term positive dc-field current is applied to strengthen the airgap flux, leading to providing a supplementary torque for boosting the engine.

\section{ANALYSIS APPROACH}

By coupling the circuit equation and the motion equation with the electromagnetic-field equation and taking into account the time-stepping rotation, the CFT-TS-FEM [22] is adopted to analyze the proposed ISG system. When the PMHB machine operates as a motor, the mathematical model consists of three sets of equations: the electromagnetic-field equation of the motor, the circuit equation of the armature windings, and the motion equation of the drive system. On the other hand, when it works as a generator, the mathematical model consists of only two sets of equations: the electromagnetic-field equation of the generator and the circuit equation of the armature windings.

The electromagnetic field equation of the proposed machine is governed by

$$
\nabla \times(\nu \nabla \times A)=J
$$

where $\nu$ is the reluctivity, $J$ is the current density, and $A$ is the magnetic vector potential. Since the end effect of this machine is not significant, the 2-D analysis is preferred. Therefore, both 

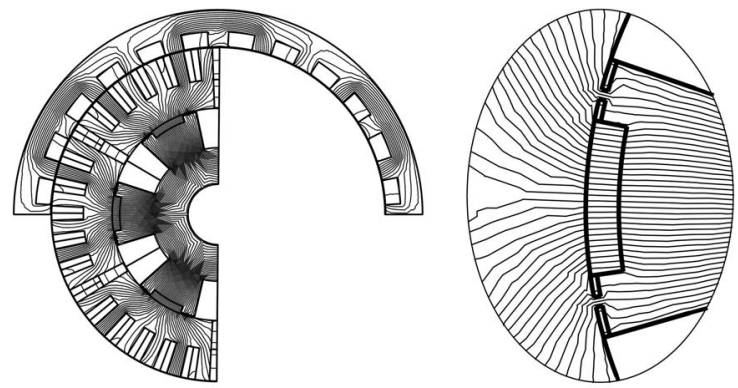

(a)

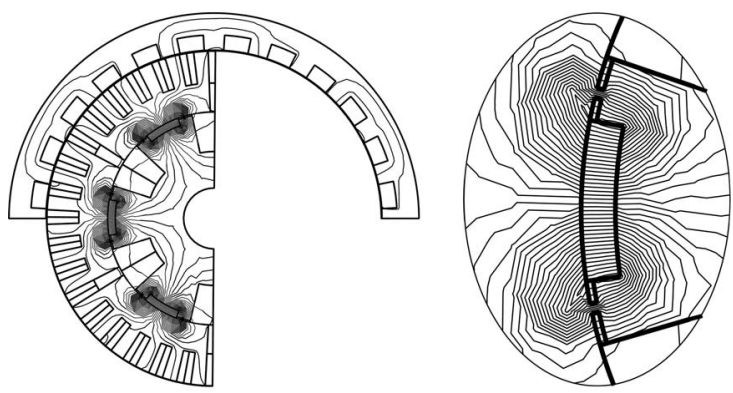

(b)

Fig. 4. Magnetic-field distributions with different dc-field currents. (a) +1000 A-turns. (b) -350 A-turns.

$J$ and $A$ have only the $z$-axis components. The corresponding 2-D electromagnetic field equation can be expressed as

$$
\begin{aligned}
\Omega: \frac{\partial}{\partial x}\left(v \frac{\partial A}{\partial x}\right)+ & \frac{\partial}{\partial y}\left(v \frac{\partial A}{\partial y}\right) \\
& =-J-v\left(\frac{\partial B_{r y}}{\partial x}-\frac{\partial B_{r x}}{\partial y}\right)+\sigma \frac{\partial A}{\partial t}
\end{aligned}
$$

where $\Omega$ is the field solution region, $\sigma$ is the electrical conductivity, $B_{r x}$ is the $x$-axis component of the PM remnant flux density, and $B_{r y}$ is the $y$-axis component of the PM remnant flux density. Along the inner periphery of the stator core and the outer periphery of the rotor core, the magnetic vector potential is assumed to be zero, i.e.,

$$
S_{1}: A=A_{z 0}=0 \text {. }
$$

The circuit equation of the machine when operating as a motor is given by

$$
\begin{aligned}
& u=R i+L_{e} \frac{d i}{d t}+e \\
& e=\frac{l}{S} \iint_{\Omega_{e}} \frac{\partial A}{\partial t} d \Omega
\end{aligned}
$$

where $u$ is the applied voltage, $R$ is the resistance per phase winding, $L_{e}$ is the inductance of the end winding, $e$ is the electromotive force (EMF) per phase, $l$ is the axial length of the iron core, $S$ is the conductor area of each turn of phase winding, and $\Omega_{e}$ is the total cross-sectional area of the conductors of each phase winding. When the machine operates as a generator, the

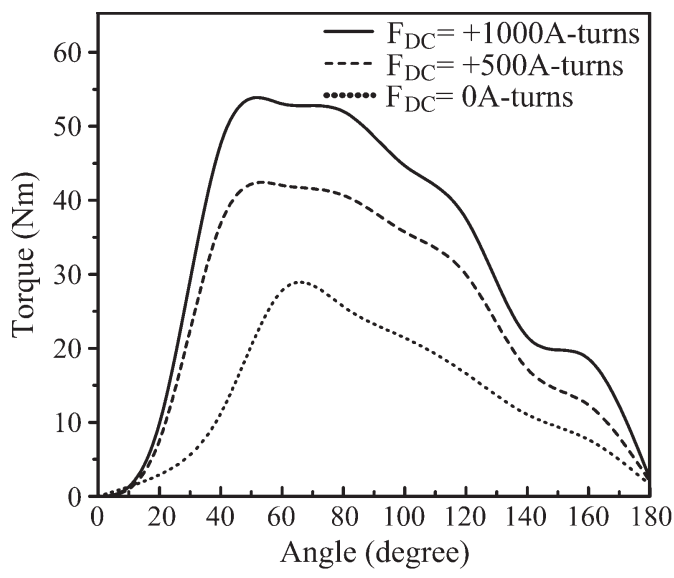

(a)

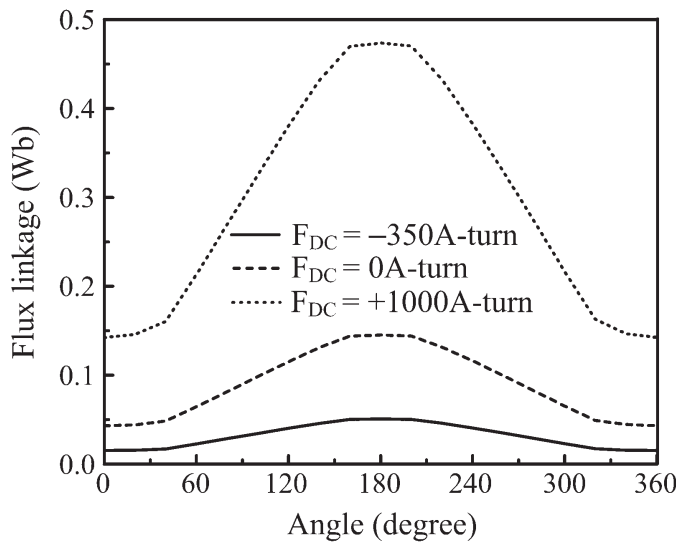

(b)

Fig. 5. Static characteristics under various dc-field currents. (a) Torque versus angle. (b) Flux linkage versus angle.

circuit equation is similar to that of the motor, except for the sign of the variables, and it can be written as

$$
u=e-R i-L_{e} \frac{d i}{d t}
$$

where $u$ stands for the generated voltage.

The motion equation of the machine is given by

$$
J_{m} \frac{d \omega}{d t}=T_{e}-T_{L}-\lambda \omega
$$

where $J_{m}$ is the moment of inertia, $\omega$ is the mechanical speed, $T_{L}$ is the load torque, and $\lambda$ is the damping coefficient.

After discretization, the aforementioned equations are solved at each time step. Consequently, both steady-state and transient performances of the proposed ISG system can be calculated.

By using the CFT-TS-FEM, the no-load magnetic-field distributions of this machine are shown in Fig. 4, in which the field pattern around a PM pole is enlarged. It can be seen that when applying a positive dc-field current, the PM flux are reinforced by the dc-field flux, hence strengthening the airgap flux. When applying a negative dc-field current, the airgap flux is effectively weakened. It can also be observed that the air bridge can avoid PM flux leakage during flux strengthening while amplifying the effect of flux weakening when the dc-field flux is opposing the PM flux. 


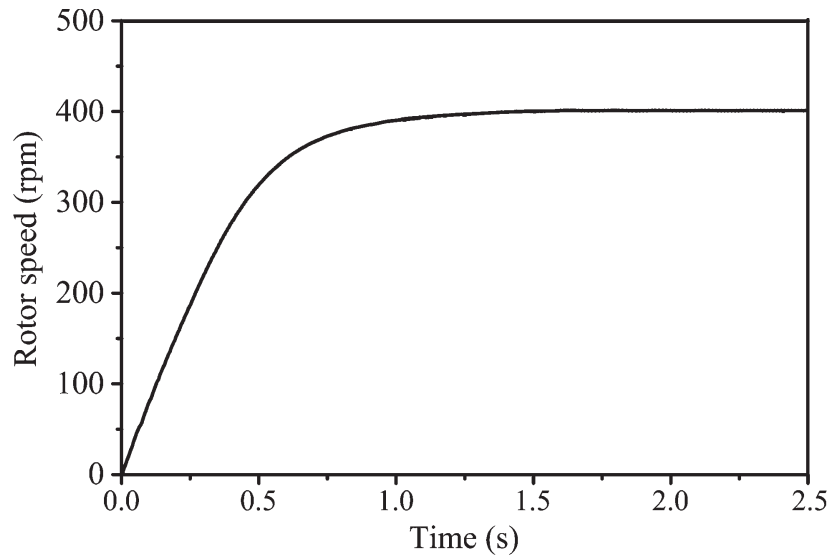

(a)

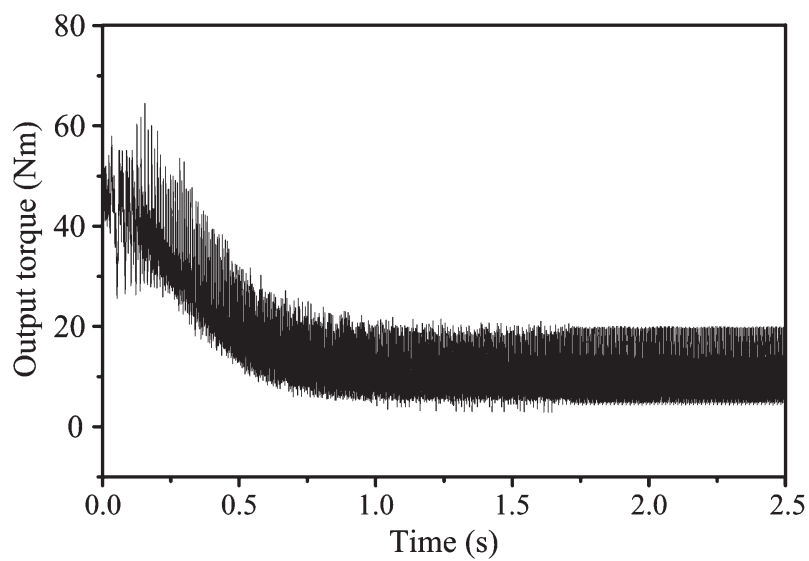

(b)

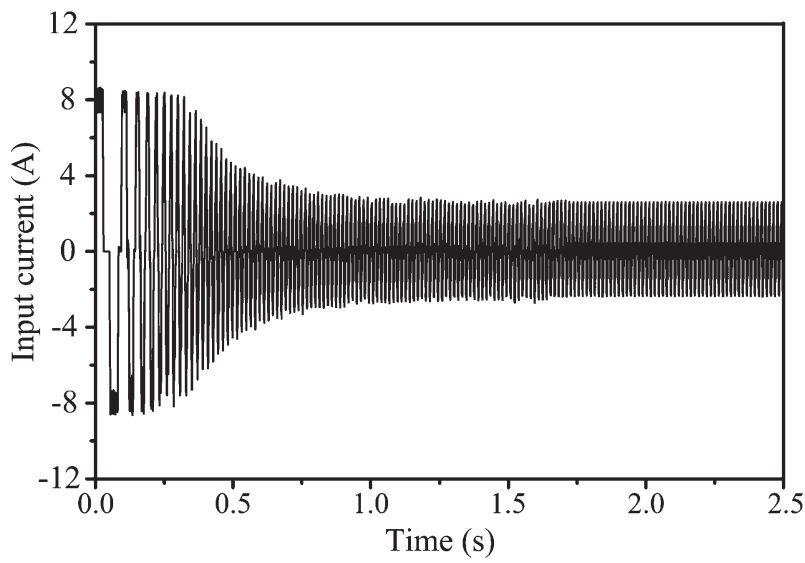

(c)

Fig. 6. Cranking performance at Mode I. (a) Rotor speed. (b) Output torque. (c) Input current.

\section{Simulation Performance}

First, when any two phases of the armature windings are fed by the rated current and the field windings are fed with different values of positive dc current, the torque-angle characteristics are calculated, as shown in Fig. 5(a). It can be seen that with the use of flux strengthening, the machine can provide a high torque even when the armature current is kept at the rated value, thus confirming its capability for cold cranking. In addition, it affirms that the output torque can be regulated by simply tuning the dc-field current. Furthermore, Fig. 5(b) shows the flux-

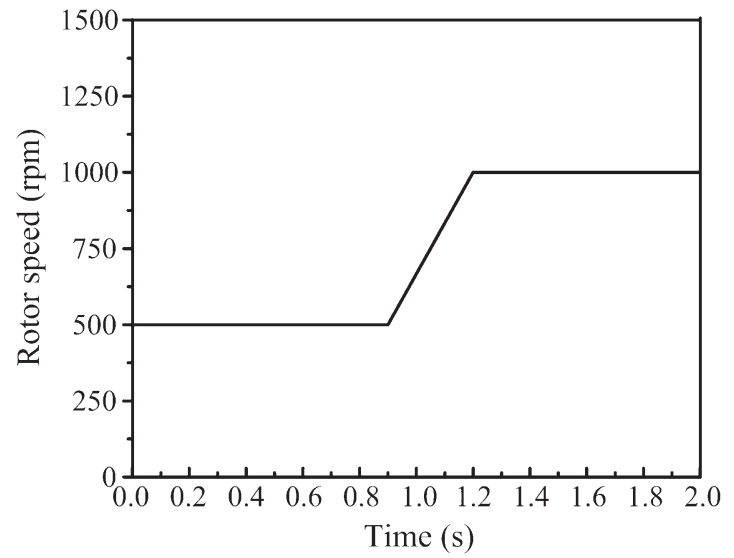

(a)

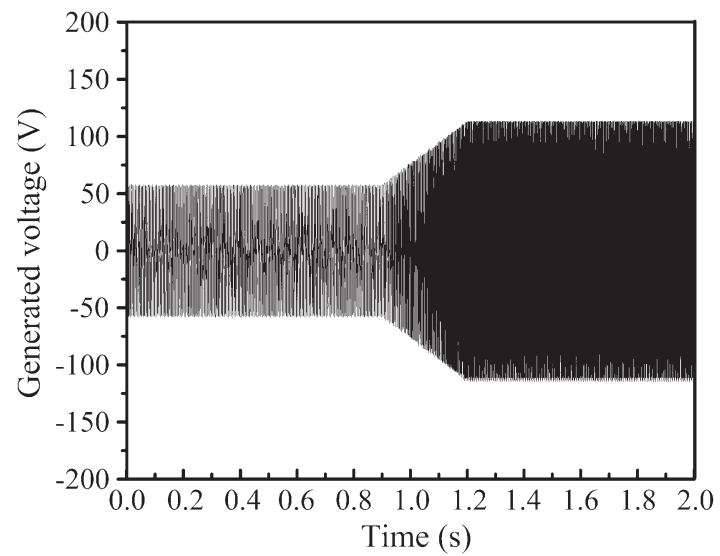

(b)

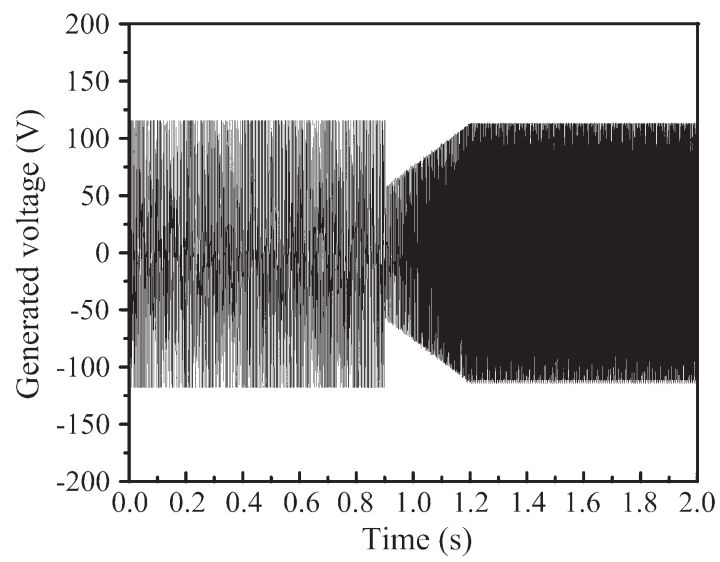

(c)

Fig. 7. Charging performance at Mode II. (a) Rotor speed. (b) Generated voltage without flux control. (c) Generated voltage with flux control.

linkage characteristics with respect to the rotor position under various dc-field excitations, including both flux strengthening and flux weakening. It confirms that the flux linkage of the proposed machine can be effectively controlled by tuning the magnitude and direction of the dc-field current.

Second, when this ISG runs in Mode I with flux strengthening of +600 A-turns, the cold-cranking performance under a load of $10 \mathrm{~N} \cdot \mathrm{m}$ is shown in Fig. 6. It can be seen that even when the armature current is clamped by the setting of 1.6 times the rated value, the machine can offer a high starting torque 


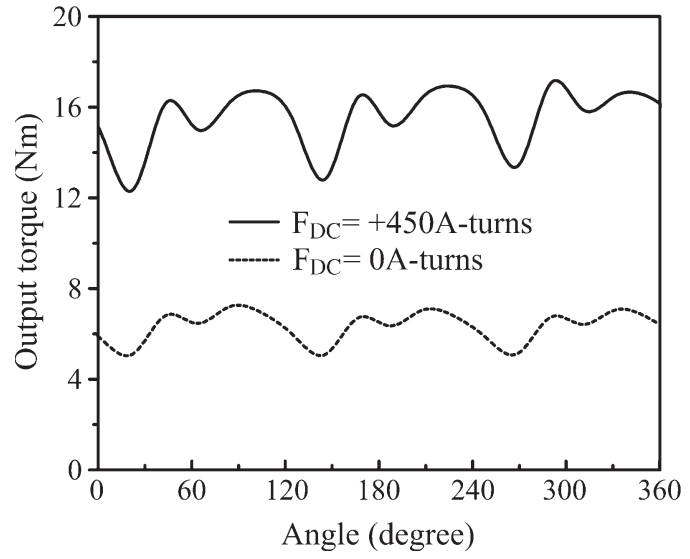

Fig. 8. Boosting performance of output torque at Mode III.

over $50 \mathrm{~N} \cdot \mathrm{m}$, which is well enough to crank the cold engine. Moreover, the corresponding speed response indicates that it can easily bring the engine into ignition within $1 \mathrm{~s}$.

Third, when the ISG runs in Mode II, the charging performance without and with flux control is simulated, as shown in Fig. 7. It can be seen that without the use of flux control, the generated voltage increases with the rotor speed. On the contrary, with flux control, the generated voltage amplitude can be kept constant. Hence, it illustrates that the ISG can provide a constant charging voltage for the battery.

Fourth, when the ISG operates in Mode III, the torqueboosting performance is assessed. Fig. 8 shows a comparison of steady-state output torques with and without flux strengthening when the armature current is kept unchanged at half the rated value. It can be seen that by applying a positive dc-field current to strengthen the airgap flux, the output torque can be significantly boosted up, hence providing the supplementary torque for hill climbing or overtaking.

\section{EXPERIMENTAL RESULTS}

The experimental setup of the proposed ISG system has been built as shown in Fig. 9. The key design data of the proposed PMHB machine is listed in Table I.

When the ISG works in Mode I, the cranking performance is measured as shown in Fig. 10. It can be found that the measured responses quite match with the simulated ones as shown in Fig. 6. Quantitatively, the transient starting torque can achieve up to $400 \%$ of the load torque under only $160 \%$ of the rated current, while the steady-state output torque is $10 \mathrm{~N} \cdot \mathrm{m}$ under only $57 \%$ of the rated current, thus verifying that the proposed ISG can provide a very good cranking performance.

When the ISG works in Mode II, the charging performances, without and with flux control, are measured as shown in Figs. 11 and 12, respectively. It can be found that the measured responses well agree with the simulated ones as shown in Fig. 7. Hence, it verifies that the proposed ISG can offer a very good charging performance. Moreover, the simulated and measured no-load EMF waveforms, without and with flux control, are shown in Figs. 13 and 14, respectively. Their agreement verifies that the ISG, with the use of flux control, is able to keep the generated voltage constant over nine times the speed range.

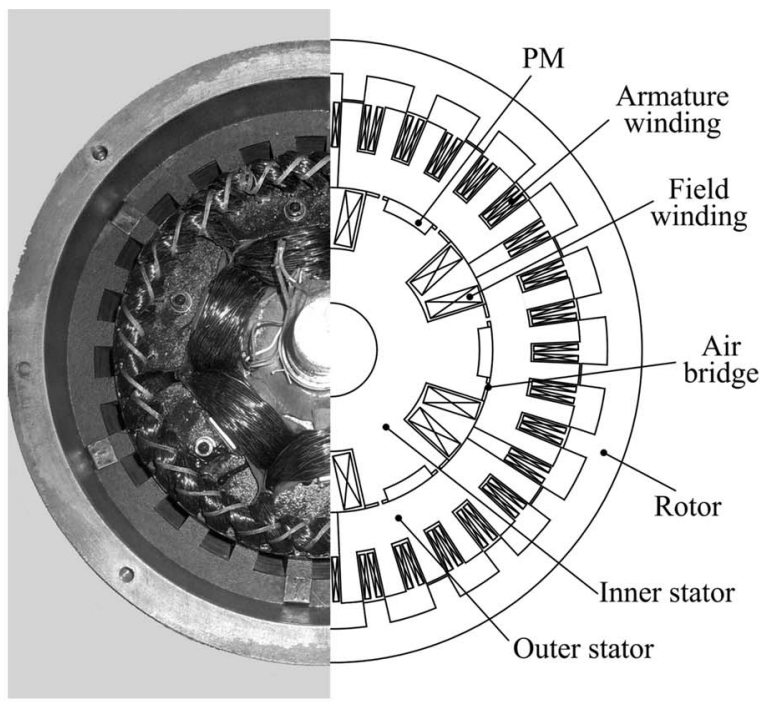

(a)

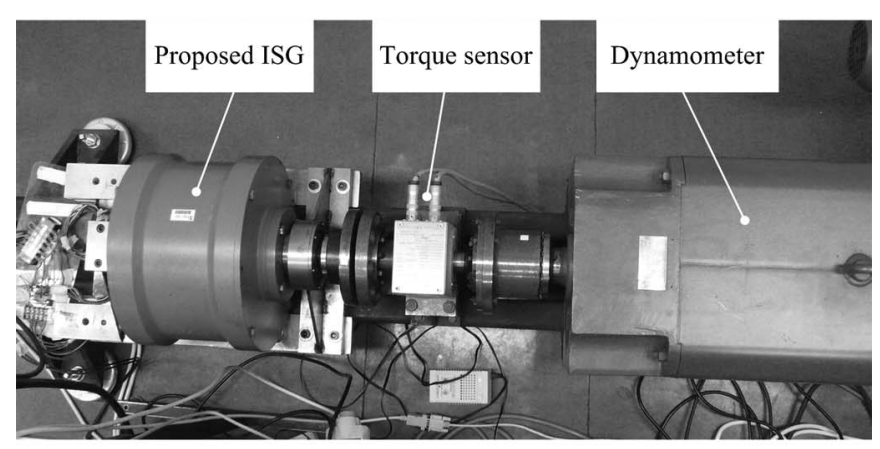

(b)

Fig. 9. Experimental setup. (a) Prototype. (b) Test bed.

TABLE I

MACHINE KeY DATA

\begin{tabular}{ll}
\hline \hline Rated Power & $2 \mathrm{~kW}$ \\
Rated current & $5.25 \mathrm{~A}$ \\
Rated torque & $20 \mathrm{Nm}$ \\
Speed range & $0 \sim 4000 \mathrm{rpm}$ \\
Number of rotor poles & 24 \\
Number of stator poles & 36 \\
Number of AC phases & 3 \\
Number of turns per armature slot & 92 \\
Number of turns per field slot & 300 \\
Rotor outside diameter & $270.0 \mathrm{~mm}$ \\
Rotor inside diameter & $221.2 \mathrm{~mm}$ \\
Stator outside diameter & $220.0 \mathrm{~mm}$ \\
Stator inside diameter & $40.0 \mathrm{~mm}$ \\
Rotor pole arc & $7^{\circ} 40^{\prime}$ \\
Rotor pole height & $10.0 \mathrm{~mm}$ \\
Stator pole arc & $5^{\circ}$ \\
Stator pole height & $22.0 \mathrm{~mm}$ \\
Airgap length & $0.6 \mathrm{~mm}$ \\
Air-bridge length & $1.0 \mathrm{~mm}$ \\
Stack length & $80.0 \mathrm{~mm}$ \\
PM thickness & $5.0 \mathrm{~mm}$ \\
PM remanent flux density & $1.1 \mathrm{~T}$ \\
PM material & $\mathrm{Nd}-\mathrm{Fe}-\mathrm{B}$ \\
\hline \hline
\end{tabular}

After rectification, the corresponding charging-voltage characteristics with respect to rotor speed and load current are shown in Fig. 15. It can be observed that the charging voltage, with the use of flux control, can be kept constant not only over a wide 


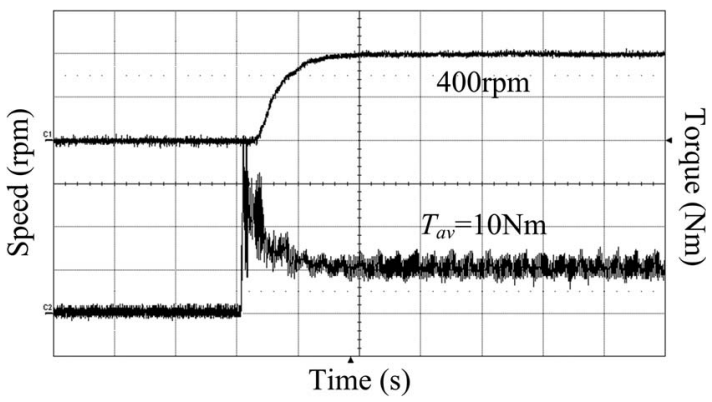

(a)

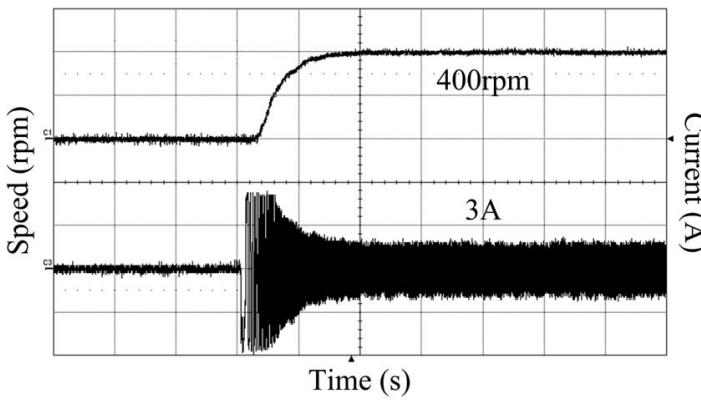

(b)

Fig. 10. Measured cranking performance at Mode I. (a) Rotor speed and output torque ( $200 \mathrm{r} / \mathrm{min} / \mathrm{div}, 10 \mathrm{~N} \cdot \mathrm{m} / \mathrm{div}, 1 \mathrm{~s} / \mathrm{div})$. (b) Rotor speed and input current (200 r/min/div, $5 \mathrm{~A} /$ div, $1 \mathrm{~s} /$ div $)$.

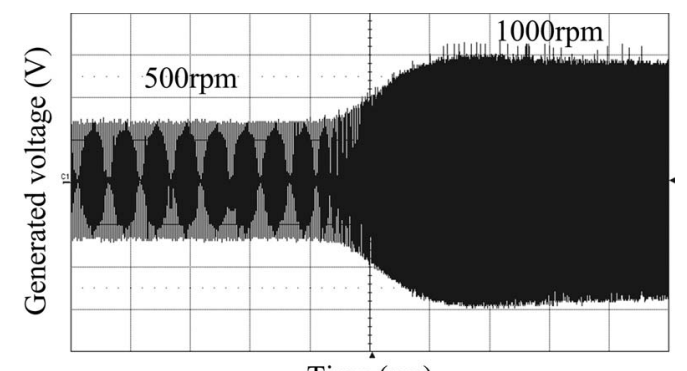

Time (ms)

(a)

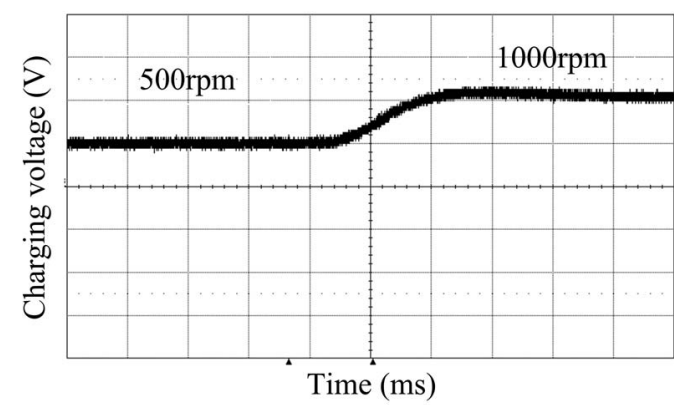

(b)

Fig. 11. Measured charging performance at Mode II without flux control. (a) Generated voltage (50 V/div, $200 \mathrm{~ms} / \mathrm{div})$. (b) Charging voltage (100 V/div, $200 \mathrm{~ms} / \mathrm{div})$.

range of rotor speed but also over a wide range of load current. Hence, it further verifies that the proposed ISG can serve as a constant-voltage generator for directly charging the battery at various rotor speeds and load currents.

When the ISG works in Mode III, the boosting performance of the output torque is measured as shown in Fig. 16. As compared with the simulated waveforms shown in Fig. 8, the

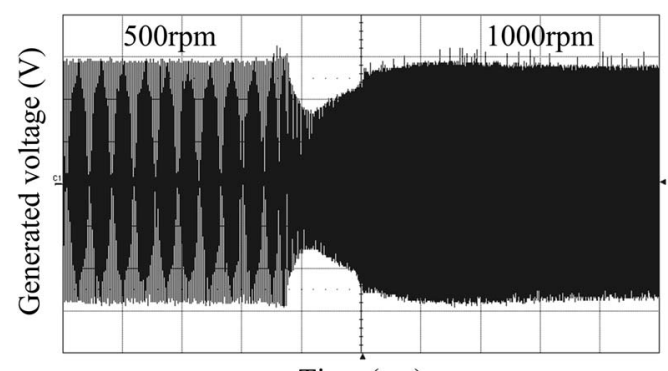

Time (ms)

(a)

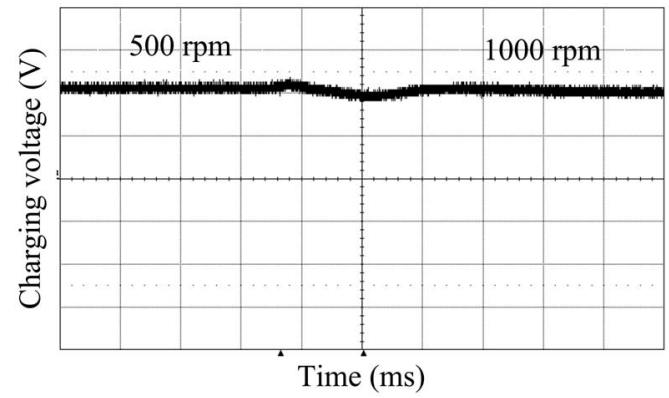

(b)

Fig. 12. Measured charging performance at Mode II with flux control. (a) Generated voltage (50 V/div, $200 \mathrm{~ms} / \mathrm{div})$. (b) Charging voltage (100 V/div, $200 \mathrm{~ms} / \mathrm{div})$.

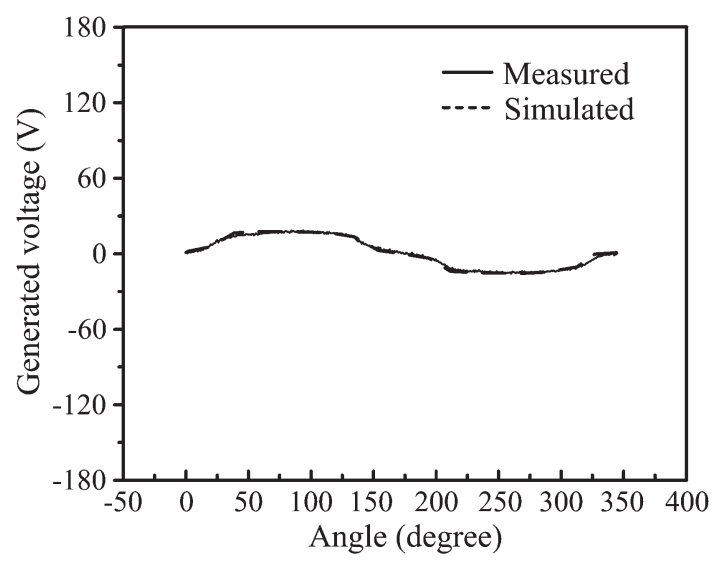

(a)

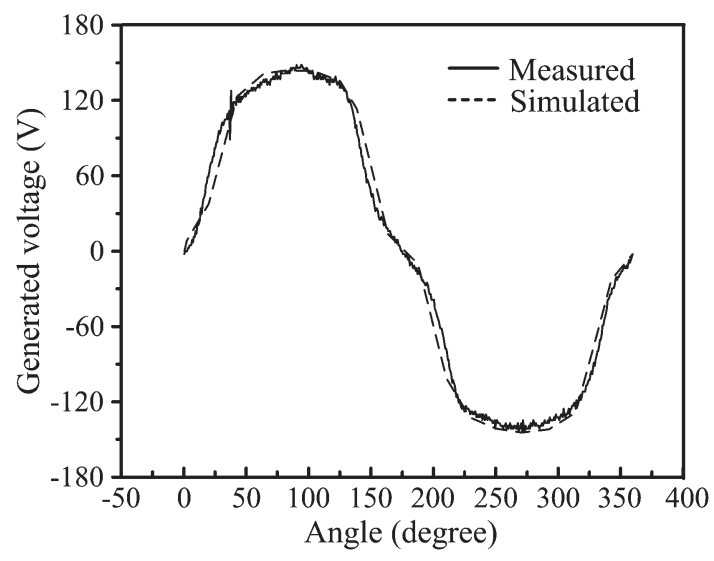

(b)

Fig. 13. Comparison of generated voltage waveforms at Mode II under various speeds without flux control. (a) $135 \mathrm{r} / \mathrm{min}$. (b) $1200 \mathrm{r} / \mathrm{min}$. 


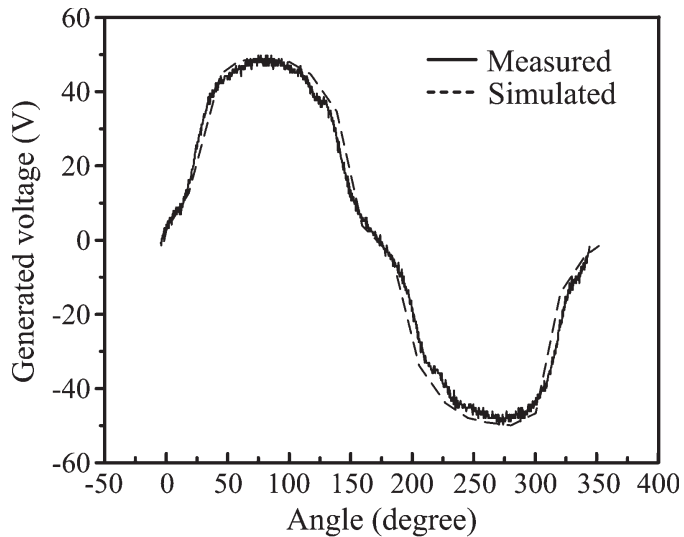

(a)

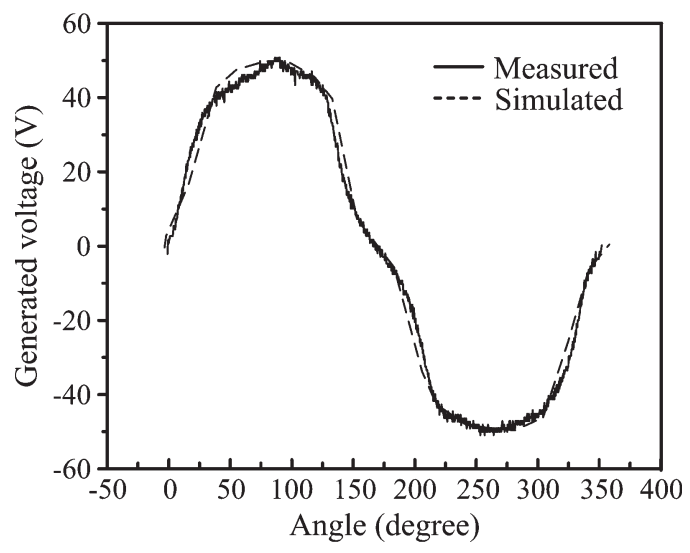

(b)

Fig. 14. Comparison of generated voltage waveforms at Mode II under various speeds with flux control. (a) $135 \mathrm{r} / \mathrm{min}$. (b) $1200 \mathrm{r} / \mathrm{min}$.

agreement is very good. Quantitatively, the measured averagetorque value is boosted from 6 to $15 \mathrm{~N} \cdot \mathrm{m}$, while the simulated value is from 6.2 to $15.1 \mathrm{~N} \cdot \mathrm{m}$. Moreover, with flux control, the measured and simulated torque ripples are $30.9 \%$ and $32.7 \%$, respectively, which are significantly lower than that of the DSPM machine (typically $80 \%-150 \%$ ) or the SR machine (typically over $150 \%$ ) [23]. It is actually due to the use of multipole concentrated winding structure. Therefore, it illustrates that the proposed ISG can offer the desired torqueboosting capability. Moreover, in order to assess the transient performance of the ISG operating in Mode III, a sudden load change is applied during a constant-speed operation, which is essential to enable the HEV offering constant speed when crossing road humps or even hill climbing. Fig. 17 shows the measured responses under a sudden load change. It can be observed that with the use of flux strengthening, the ISG can quickly boost the output torque from 4 to $7 \mathrm{~N} \cdot \mathrm{m}$, while the armature current can be kept at a low level. It is worthy to mention that the instantaneous torque can achieve up to $42 \mathrm{~N} \cdot \mathrm{m}$ ( $210 \%$ of the rated torque) when the instantaneous armature current is only $6.2 \mathrm{~A}$ (118\% of the rated current).

Apart from the aforementioned three major modes of operation, the ISG can provide other sophisticated modes of operation, such as for torque or speed damping when the HEV runs on a bumpy road. Fig. 18 shows the measured responses of output torque under sudden speed changes, namely, for

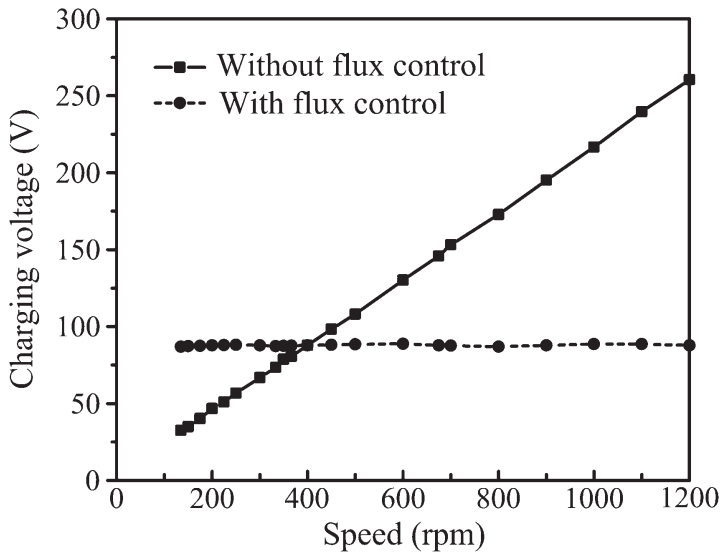

(a)

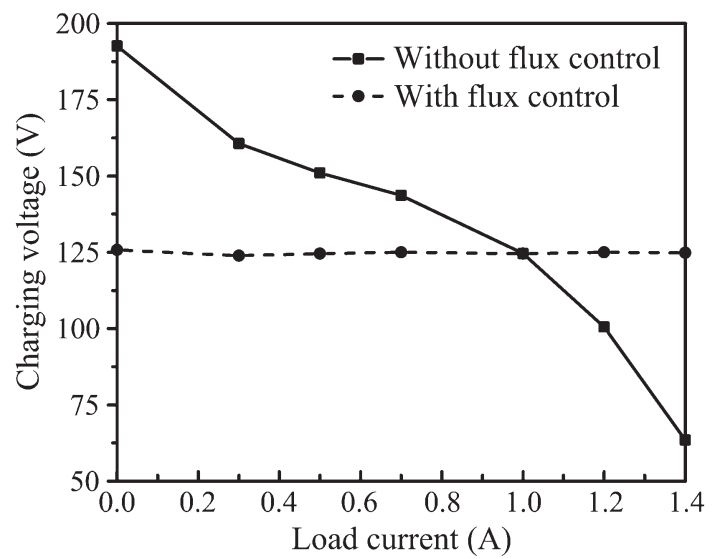

(b)

Fig. 15. Measured characteristics at Mode II. (a) Charging voltage versus rotor speed at no load. (b) Charging voltage versus load current at $900 \mathrm{r} / \mathrm{min}$.

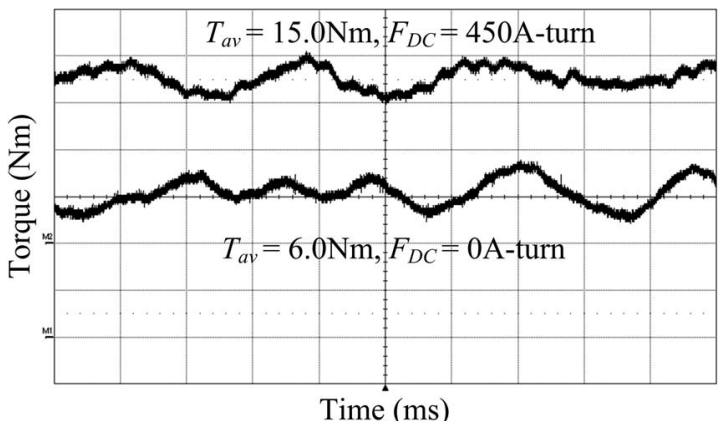

Fig. 16. Measured boosting performance of output torque at Mode III (upper: $4 \mathrm{~N} \cdot \mathrm{m} / \mathrm{div}, 10 \mathrm{~ms} / \mathrm{div}$; lower: $2 \mathrm{~N} \cdot \mathrm{m} / \mathrm{div}, 10 \mathrm{~ms} / \mathrm{div}$ ).

acceleration and deceleration of the HEV. It can be observed that the output torque can be maintained almost constant, hence illustrating that the ISG can perform torque damping for the HEV.

\section{DISCUSSION}

In order to further demonstrate the merits of the proposed PMHB machine, a comparison with the traditional machine is conducted. Since the proposed machine is a kind of stator-PM brushless machines, the traditional DSPM machine is selected for comparison. Based on the same outer-rotor structure with 


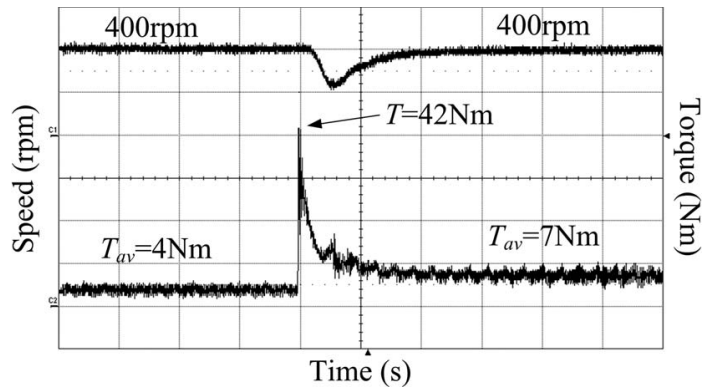

(a)

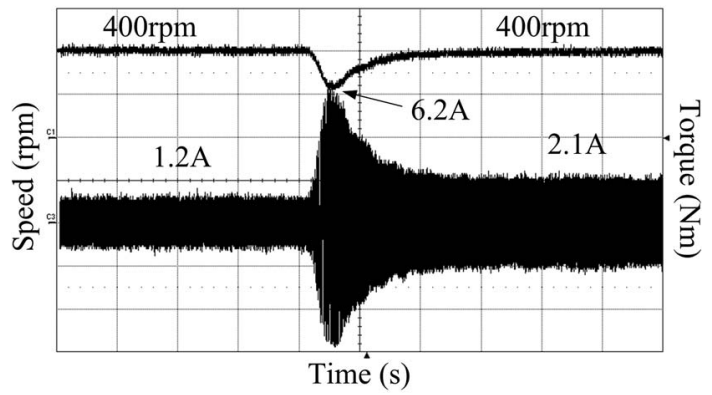

(b)

Fig. 17. Measured boosting performance at Mode III under sudden load change. (a) Rotor speed and output torque ( $200 \mathrm{r} / \mathrm{min} / \mathrm{div}, 10 \mathrm{~N} \cdot \mathrm{m} / \mathrm{div}, 1 \mathrm{~s} / \mathrm{div})$. (b) Rotor speed and input current ( $200 \mathrm{r} / \mathrm{min} / \mathrm{div}, 2 \mathrm{~A} / \mathrm{div}, 1 \mathrm{~s} / \mathrm{div})$.

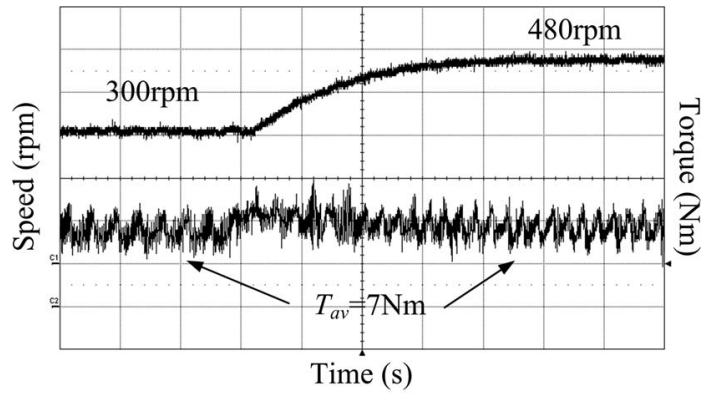

(a)

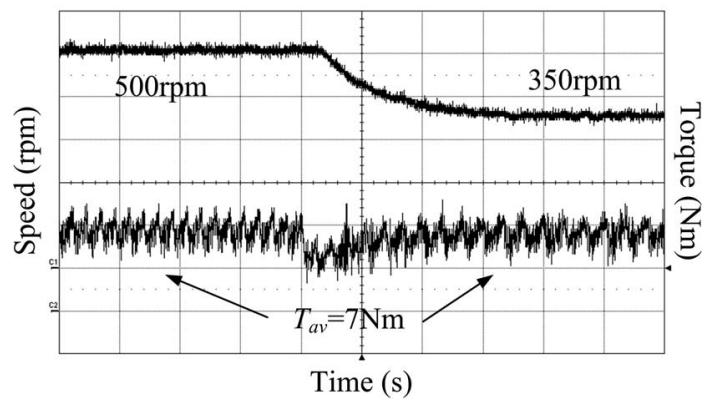

(b)

Fig. 18. Measured constant output torque under sudden speed changes. (a) Acceleration $(100 \mathrm{r} / \mathrm{min} / \mathrm{div}, 4 \mathrm{~N} \cdot \mathrm{m} / \mathrm{div}, 1 \mathrm{~s} / \mathrm{div})$. (b) Deceleration (100 r/min/div, $4 \mathrm{~N} \cdot \mathrm{m} / \mathrm{div}, 1 \mathrm{~s} / \mathrm{div})$.

the same peripheral diameter and axial length, their torque densities are calculated by using the CFT-TS-FEM, as listed in Table II. It can be found that the gravimetric and volumetric rated torque densities of the proposed machine are, respectively, $13.6 \%$ and $9.1 \%$ smaller than that of the DSPM one. It is expected since the PMHB machine incorporates additional copper windings for dc-field excitation. Nevertheless, due to
TABLE II

TORQUE PERFORMANCE COMPARISON

\begin{tabular}{lcc}
\hline \hline & PMHB & DSPM \\
\hline Rated torque / mass & $0.731 \mathrm{Nm} / \mathrm{kg}$ & $0.846 \mathrm{Nm} / \mathrm{kg}$ \\
Rated torque / volume & $4.37 \mathrm{kNm} / \mathrm{m}^{3}$ & $4.81 \mathrm{kNm} / \mathrm{m}^{3}$ \\
Boosting torque / mass & $1.901 \mathrm{Nm} / \mathrm{kg}$ & $0.846 \mathrm{Nm} / \mathrm{kg}$ \\
Boosting torque / volume & $11.36 \mathrm{kNm} / \mathrm{m}^{3}$ & $4.81 \mathrm{kNm} / \mathrm{m}^{3}$ \\
\hline \hline
\end{tabular}

the boosting capability of the proposed machine, it can offer boosting-torque densities of up to $124.7 \%$ and $136.2 \%$ of the DSPM one, which are highly desirable for engine cranking and torque boosting. Most importantly, the proposed machine can operate at a wide speed range (up to $4000 \mathrm{r} / \mathrm{min}$ ) and maintain a constant-voltage output for battery charging, whereas the DSPM machine can only work in a narrow speed range (up to $1200 \mathrm{r} / \mathrm{min}$ ) with the output voltage varying with the rotor speed. Therefore, the proposed PMHB machine is superior to the DSPM machine or other stator-PM brushless machines for ISG application.

It should be noted that the proposed machine is designed to enable good power transfer up to $4000 \mathrm{r} / \mathrm{min}$. If the machine operates at very high speeds (near $6000 \mathrm{r} / \mathrm{min}$ ) such as for the vehicle running at Autobahn speeds, its winding inductance will adversely affect the power transfer. Therefore, if this very high speed operation is generally desired, the machine needs to be redesigned and optimized for operation of up to $6000 \mathrm{r} / \mathrm{min}$. This optimization is feasible because the dc-field control can easily compensate for the adverse effect of winding inductance and effectively maintain a constant voltage for battery charging, while the flux weakening can efficiently suppress the highfrequency iron loss even at very high speeds.

\section{CONCLUSION}

In this paper, a new PMHB machine has been proposed and implemented as ISG for HEVs. Since the proposed PMHB machine has the unique feature of hybrid excitations (both PMs and field windings) to produce the magnetic field, it can flexibly regulate the airgap flux, hence accomplishing various operation modes, namely, engine cranking, battery charging, and torque boosting. Both the CFT-TS-FEM simulation and experimentation have confirmed the superiority of the proposed ISG system.

\section{REFERENCES}

[1] K. T. Chau and C. C. Chan, "Emerging energy-efficient technologies for hybrid electric vehicles," Proc. IEEE, vol. 95, no. 4, pp. 821-835, Apr. 2007.

[2] S. M. Lukic, J. Cao, R. C. Bansal, F. Rodriguez, and A. Emadi, "Energy storage systems for automotive applications," IEEE Trans. Ind. Electron., vol. 55, no. 6, pp. 2258-2267, Jun. 2008.

[3] F. H. Khan, L. M. Tolbert, and W. E. Webb, "Hybrid electric vehicle power management solutions based on isolated and nonisolated configurations of multilevel modular capacitor-clamped converter," IEEE Trans. Ind. Electron., vol. 56, no. 8, pp. 3079-3095, Aug. 2009.

[4] C. C. Chan, K. T. Chau, J. Z. Jiang, W. Xia, M. Zhu, and R. Zhang, "Novel permanent magnet motor drives for electric vehicles," IEEE Trans. Ind. Electron., vol. 43, no. 2, pp. 331-339, Apr. 1996.

[5] Z. Q. Zhu and D. Howe, "Electrical machines and drives for electric, hybrid and fuel cell vehicles," Proc. IEEE, vol. 95, no. 4, pp. 746-765, Apr. 2007. 
[6] J. W. Finch and D. Giaouris, "Controlled AC electrical drives," IEEE Trans. Ind. Electron., vol. 55, no. 2, pp. 331-339, Feb. 2008.

[7] K. T. Chau, C. C. Chan, and C. Liu, "Overview of permanent-magnet brushless drives for electric and hybrid electric vehicles," IEEE Trans. Ind. Electron., vol. 55, no. 6, pp. 2246-2257, Jun. 2008.

[8] M.-J. Yang, H.-L. Jhou, B.-Y. Ma, and K. K. Shyu, "A cost-effective method of electric brake with energy regeneration for electric vehicles," IEEE Trans. Ind. Electron., vol. 56, no. 6, pp. 2203-2212, Jun. 2009.

[9] W. Cai, "Comparison and review of electric machines for integrated starter alternator applications," in Conf. Rec. IEEE IAS Annu. Meeting, 2004, pp. 386-393.

[10] P. Bajec, B. Pevec, D. Voncina, D. Miljavec, and J. Nastran, "Extending the low-speed operation range of PM generator in automotive applications using novel ac-dc converter control," IEEE Trans. Ind. Electron., vol. 52, no. 2, pp. 436-443, Apr. 2005

[11] C. Liu, K. T. Chau, J. Z. Jiang, X. Liu, and Z. Wang, "Design and control of a doubly-excited permanent-magnet brushless integrated-startergenerator for hybrid electric vehicles," in Conf. Rec. IEEE IAS Annu. Meeting, 2007, pp. 1702-1709.

[12] J. Zhang and M. F. Rahman, "A direct-flux-vector-controlled induction generator with space-vector modulation for integrated starter alternator," IEEE Trans. Ind. Electron., vol. 54, no. 5, pp. 2512-2520, Oct. 2007.

[13] B. Fahimi, A. Emadi, and R. B. Sepe, "A switched reluctance machinebased starter/alternator for more-electric cars," IEEE Trans. Energy Convers., vol. 19, no. 1, pp. 116-124, Mar. 2004.

[14] D.-H. Lee, J. Liang, Z.-G. Lee, and J.-W. Ahn, "A simple nonlinear logical torque sharing function for low-torque ripple SR drive," IEEE Trans. Ind. Electron., vol. 56, no. 8, pp. 3021-3028, Aug. 2009.

[15] A. Emadi, Y. J. Lee, and K. Rajashekara, "Power electronics and motor drives in electric, hybrid electric, and plug-in hybrid electric vehicles," IEEE Trans. Ind. Electron., vol. 55, no. 6, pp. 2237-2245, Jun. 2008.

[16] L. Chedot, G. Friedrich, J.-M. Biedinger, and P. Macret, "Integrated starter generator: The need for an optimal design and control approach, application to a permanent magnet machine," IEEE Trans. Ind. Electron., vol. 43, no. 2, pp. 551-559, Mar./Apr. 2007.

[17] D. Zhang, K. T. Chau, S. Niu, and J. Z. Jiang, "Design and analysis of a double-stator cup-rotor PM integrated-starter-generator," in Conf. Rec. IEEE IAS Annu. Meeting, 2006, pp. 20-26.

[18] E. Spooner, S. A. W. Khatab, and N. G. Nicolaou, "Hybrid excitation of AC and DC machines," in Proc. Int. Conf. Electr. Mach. Drives, 1989, pp. $48-52$.

[19] M. Aydin, S. Huang, and T. A. Lipo, "A new axial flux surface mounted permanent magnet machine capable of field control," in Conf. Rec. IEEE IAS Annu. Meeting, 2002, pp. 1250-1257.

[20] J. A. Tapia, F. Leonardi, and T. A. Lipo, "Consequent-pole permanentmagnet machine with extended field-weakening capability," IEEE Trans. Ind. Appl., vol. 39, no. 6, pp. 1704-1709, Nov./Dec. 2003.

[21] C. Liu, K. T. Chau, J. Z. Jiang, and L. Jian, "Design of a new outer-rotor permanent magnet hybrid machine for wind power generation," IEEE Trans. Magn., vol. 44, no. 6, pp. 1494-1497, Jun. 2008.

[22] Y. Wang, K. T. Chau, C. C. Chan, and J. Z. Jiang, "Transient analysis of a new outer-rotor permanent-magnet brushless dc drive using circuit-fieldtorque time-stepping finite element method," IEEE Trans. Magn., vol. 38, no. 2, pp. 1297-1300, Mar. 2002.

[23] K. T. Chau, Q. Sun, Y. Fan, and M. Cheng, "Torque ripple minimization of doubly salient permanent-magnet motors," IEEE Trans. Energy Convers., vol. 20, no. 2, pp. 352-358, Jun. 2005.

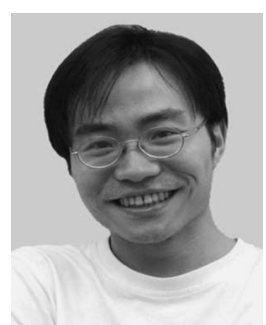

Chunhua Liu (S'05-M'10) received the B.Eng. and M.Eng. degrees from the Department of Automatic Control, Beijing Institute of Technology, Beijing, China, in 2002 and 2005, respectively, and the Ph.D degree from the Department of Electrical and Electronic Engineering, The University of Hong Kong, Hong Kong, in 2009.

He is currently a Researcher with the Department of Electrical and Electronic Engineering, The University of Hong Kong. His research interests include electric drives, electric vehicles, renewable energy developments, vehicle to grid, and smart-grid systems. He currently focuses on the design of permanent-magnet brushless motors, integrated-starter-generator systems, and electric variable transmission systems for hybrid electric vehicles, as well as the development of wind power versus photovoltaic generation systems and the smart energy delivery.

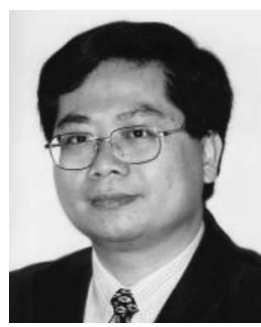

K. T. Chau (M'89-SM'04) received the B.Sc. (Eng.) (First-Class Honors), M.Phil., and Ph.D. degrees in electrical and electronic engineering from The University of Hong Kong, Hong Kong, in 1988, 1991, and 1993, respectively.

He is currently a Professor with the Department of Electrical and Electronic Engineering, The University of Hong Kong, where he is also Director of the International Research Center for Electric Vehicles. His teaching and research interests focus on three main areas: electric vehicles, electric drives, and power electronics. In these areas, he has published over 300 refereed technical papers. He is also the coauthor of the monograph, Modern Electric Vehicle Technology (London, U.K.: Oxford Univ. Press, 2001).

Dr. Chau is a Fellow of IET. He was the recipient of the Outstanding Young Researcher Award in 2003, the University Teaching Fellowship Award in 2004, and the Award for Innovative Excellence in Teaching, Learning, and Technology in 2005 .

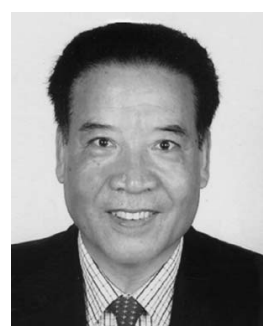

J. Z. Jiang received the B.E.E. and M.E.E. degrees from Shanghai Jiao-Tong University, Shanghai, China, in 1962 and 1965, respectively, and the Dr.-Ing. degree from the Technical University of Braunschweig, Braunschweig, German, in 1988.

$\mathrm{He}$ is currently a Professor with the Department of Automation, Shanghai University, Shanghai. His research interests are in high-performance variablespeed drives, electric machine design, numerical analysis of electromagnetic fields in electric machinery, the dynamic modeling of machines, and their 